\title{
Remission and Worsening of Claudication on MRI
}

\author{
Masahiro Kimura, Takao Kato, Shoichi Miyamoto and Moriaki Inoko
}

Key words: cystic adventitial disease, peripheral artery disease, MRI

(Intern Med 54: 89-90, 2015)

(DOI: 10.2169/internalmedicine.54.3105)

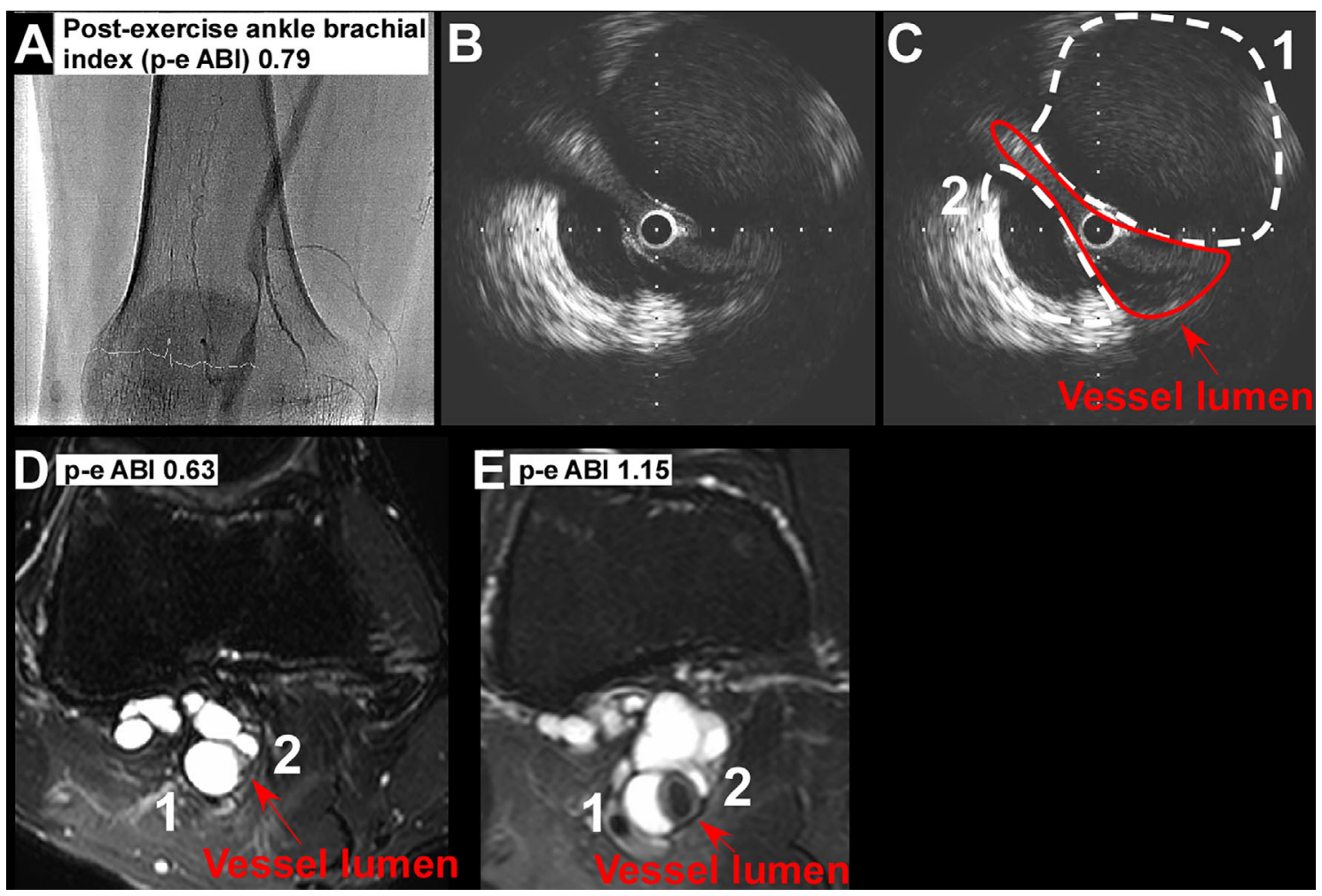

Picture.

A 43-year-old man admitted for right leg claudication exhibited eccentric stenosis of the popliteal artery on angiography (Picture A). Atherosclerosis, thrombosis or angiitis was suspected in this young patient (1); however, intravascular ultrasonography detected various echogenic masses pressing on the vessel's external elastic membrane (Picture B, C). Magnetic resonance imaging (MRI) showed multilocular cysts with high intensity on T2-weighted images. A diagnosis of cystic adventitial disease (CAD) led us to perform percutaneous aspiration, the results of which showed yellow mucinous gel. However, the patient's symptoms recurred with cyst regrowth three months later (Picture D). Although surgical resection was considered to treat the recurrence, his symptoms improved eight months later with movement of the contents through connections between the cysts with an enlarged lumen (Picture E). While the precise mechanisms of remission or worsening of CAD, a rare but important cause of claudication in young patients, remain unknown (2), sequential MRI may provide clues to diagnosis.

The authors state that they have no Conflict of Interest (COI). 
Intern Med 54: 89-90, 2015 DOI: 10.2169/internalmedicine.54.3105

\section{References}

1. Shimizu T, Kagawa H, Katsura K, et al. Polyangiitis overlap syn-

drome. Intern Med 36: 524-527, 1997.

\author{
(C) 2015 The Japanese Society of Internal Medicine
http://www.naika.or.jp/imonline/index.html \\ (C) 2015 The Japanese Society of Internal Medicin
http://www.naika.or.jp/imonline/index.html
}

2. Pursell R, Torrie EP, Gibson M, Galland RB. Spontaneous and permanent resolution of cystic adventitial disease of the popliteal artery. J R Soc Med 97: 77, 2004. 